\title{
Changes of Anthocyanins in Black Rice Flours Prepared by Cooking and Pregelatinization
}

\author{
Sudarat Jiamyangyuen ${ }^{1 *}$, Nitra Nuengchamnong ${ }^{2}$, \\ and Paradorn Ngamdee ${ }^{3}$
}

\begin{abstract}
${ }^{1}$ Department of Agro-Industry, Faculty of Agriculture, Natural Resources and Environment, Naresuan University, Phitsanulok 65000, Thailand

${ }^{2}$ Science Laboratory Centre, Faculty of Science, Naresuan University, Phitsanulok 65000, Thailand

${ }^{3}$ Department of Food Science and Technology, Faculty of Science and Technology, Thepsatri Rajabhat University, Lopburi 15000, Thailand

*Corresponding author. E-mail: sudaratj@nu.ac.th

https://doi.org/10.12982/CMUJNS.2019.0035
\end{abstract}

Received: October 7, 2018

Revised: March 7, 2019

Accepted: April 24, 2019

\begin{abstract}
Black rice is considered healthier than white rice as it contains anthocyanins which have been claimed to have multiple health benefits. The wide application of black rice is limited due to the limiting properties of native rice flour. The Thai black rice cultivar, Niew Dam (ND; glutinous type) and Hom Nil (HN; non-glutinous type), were pregelatinized through conventional cooking (C) followed by drum-drying (D). The effects of the heat treatments on physical and chemical properties, anthocyanin content, and antioxidant activity were determined. Rice flour with no heat treatment (native: $N$ ) showed lower hydration values compared to those of cooked and drum dried samples. Total anthocyanin contents $(T A C)$ of $N D-N, N D-C$, and ND-D (4,099, 452, and $358 \mathrm{mg} / 100 \mathrm{~g} \mathrm{dw}$, respectively) were significantly higher than those of $\mathrm{HN}-\mathrm{N}$, $\mathrm{HN}-\mathrm{C}, \mathrm{HN}-\mathrm{D}(305,95$, and $23 \mathrm{mg} / 100 \mathrm{~g} \mathrm{dw}$, respectively). After cooking and drum-drying processes, the retention percentage of TAC in ND-D and HN-D were $9 \%$ and $8 \%$, respectively. Specific anthocyanin compounds, namely cyanidin-3-glucoside and peonidin-3-glucoside, were significantly decreased in both rice cultivars after cooking and the drum-drying processes. The LC-ESI-QTOF was able to identify cyanidin-3-sambubioside for the first time
\end{abstract}


in black rice. Compared to untreated grains, the antioxidant activity of the drum dried samples was decreased by approximately $20 \%$ indicating reasonable preservation of the antioxidant benefits. The improvement of physical properties and the remaining anthocyanin content of the pre-gelatinized black rice flour indicates that it has a potential application as an ingredient in healthier food products.

Keywords: Anthocyanin, Black rice, Drum-drying, Pregelatinization

\section{INTRODUCTION}

Rice is a staple food for people in many countries in Asia and consumption is increasing in other areas around the world. Different rice varieties are commercially available in the market. In Thailand, both glutinous and non-glutinous rice cultivars are mostly consumed as cooked rice or as an ingredient in sweet dishes. Recently, pigmented rice, including black, red, or purple types, has received more attention due to claimed health benefiting from specific compounds in the bran layers. Black rice (Oryza sativa L. indica), grains, which have a dark purple (so-called black color) appearance, contain anthocyanins which have been shown to have multiple health benefits, including prevention of cardiovascular diseases and some cancers (He and Giusti, 2010). The major anthocyanin compounds in black rice are cyanidin-3-glucoside and peonidin-3-glucoside (Pereira-Caro et al., 2013). Although it has been recognized that pigmented rice selections provide higher health benefits than white rice, the consumption of black rice remain very low.

In addition to direct consumption of rice as cooked grains, rice is also processed to flour for a number of broader applications. Although black rice flour is currently commercially available, its applications are still limited due to inherent characteristics such as the presence of starch granules, low water solubility, and an undesirable amylose/amylopectin ratio (Miles et al., 1985). One approach that can be used to modify the starch in rice grains is a pregelatinization process, which involves the use of heat from a drum dryer, a spray dryer, or an extruder (Lai, 2001). The pregelatinization process could possibly alter rice flour so that it has better properties such as improved water absorption, solubility, pasting property, storage stability, and reduced starch retrogradation (Juliano, 1984; Miles et al., 1985). With improved properties, the pregelatinized starch would be suitable for various food applications and create healthier food products, such as porridges, soups, and beverages (Juliano, 1984). 
Changes of nutritional components, as well as phytochemicals in rice, are observed after processing. The effects of cooking on the concentrations of bioactive compounds, including carotenoids, total phenolics, and anthocyanins of some pigmented rice cultivars were investigated by Melini et al. (2019) who reported that after cooking, the concentrations of total lutein, free phenolic compounds and anthocyanin were significantly decreased $(P<0.05)$, but insoluble-bound phenolic compounds were increased. Anthocyanin content is usually lost during different processing methods (e.g. soaking, cooking, and baking) as anthocyanins are water soluble molecules and susceptible to degradation at high temperatures (Hiemori et al., 2009). Losses of the major antioxidant compounds after a range of cooking processes, as measured by changes in anthocyanin concentration and DPPH activity of four non-glutinous and four glutinous genotypes, were reported by Yamuangmorn et al. (2018). They also found that the loss of anthocyanain was greater in non-glutinous than in glutinous genotypes. Effects of drum-drying on physical and antioxidant properties of riceberry flour were reported by Wiriyawattana et al. (2018). An increased drum-drying temperature resulted in decreased phenolic content and antioxidant capacity.

In this study, two rice samples were cooked and then subjected to a starch modification process using drum drying. Presently, little information is available regarding changes of black rice flour properties as affected by either of these processes. This work, therefore, aimed to study the effect of the cooking and pregelatinization process on the anthocyanin content, antioxidant activities, and functional properties of pregelatinized flour produced from two black rice cultivars. The changes in the anthocyanin content at each of the two steps of the modification process (cooking and drum-drying) was determined using HPLC-DAD analysis. The LC-ESI-QTOF analysis was employed to identify possible new anthocyanin derivatives. The modified black rice flour could create a business opportunities and increase the use of black rice for an alternative healthy ingredient in the food industry.

\section{MATERIALS AND METHODS}

\section{Chemicals}

The chemicals used for the antioxidant assay were 1,1-diphenyl-2-picrylhydrazyl (DPPH) (Fluka, Germany) and gallic acid monohydrate (Sigma, USA). Solvents used in the experiment were analytical grade. Mobile phase solvents (water and ACN) were of HPLC grade and purchased from RCI LabScan, Thailand. Anthocyanin standards, cyanidin-3-glucoside chloride (C3G) and peonidin-3-glucoside chloride (P3G), were purchased from Sigma, USA. 


\section{Rice samples}

Two black rice cultivars, glutinous black rice (Niew Dam; ND) and non-glutinous black rice (Hom Nil; HN), were cultivated in Phetchabun province in Thailand and were obtained directly from the farmer on January 2015. The paddy rice was stored in polyethylene bags to prevent moisture loss and insect attack and kept in a refrigerator at $4 \pm 1^{\circ} \mathrm{C}$.

\section{Preparation of native black rice flour}

The paddy rice was milled using a small electric rice milling machine (NW1000 TURBO, Natrawee Technology Co., Ltd.). The black rice grains were then ground using an electric grinder (Puluerisette-14, Fritsch) at 13,000 rpm and sieved using a sieving machine (Retsch 6695-018-026) equipped with a sieve aperture of $150 \mu \mathrm{m}$ (Mesh No. 100). This black rice flour was labeled as native rice flour $(\mathrm{N})$ and was kept in a polyethylene bag in the dark.

\section{Preparation of cooked and pregelatinized black rice flour}

The cooked and pregelatinized black rice flour samples were each prepared separately. The cooked rice was prepared by cooking the whole grain native rice using a conventional electric rice cooker with a ratio of rice to water of $1: 1(\mathrm{v} / \mathrm{v})$ for the non-glutinous rice and 1:1.5 for the glutinous one. The cooked rice was then dried in a hot air oven $\left(50^{\circ} \mathrm{C}, 12 \mathrm{~h}\right)$ and ground into flour and labeled as cooked rice $(\mathrm{C})$. The pregelatinized black rice flour was prepared with two consecutive steps. Firstly, the black rice was cooked using the same conditions as for the cooked rice. Secondly, the cooked rice was ground and mixed with water $(1: 2 \mathrm{w} / \mathrm{w})$ resulting in a slurry mixture. It was subsequently dried using a drum-dryer (John-Millder) following the method described by Wadchararat et al., (2006): double drum gap $=0.1 \mathrm{~mm}$, drying temperature $=130{ }^{\circ} \mathrm{C}$, and rolling speed $=12 \mathrm{rpm}$. The obtained drum-dried black rice flour thin pellets were ground into powder using an electric grinder and sieved through a sieve mesh No. 100 (sample D). The pregelatinized flour was kept in a polyethylene bag and stored at $-15 \pm 2{ }^{\circ} \mathrm{C}$ for further analysis.

\section{Color measurement}

The color of the native, cooked, and drum-dried black rice flour was measured using a HunterLab MiniScan XE PLUS (Hunter Associates Laboratory, Inc., Reston, VA) and the results were expressed as $L^{*}, a^{*}$ and $b *$ color coordinates. 


\section{Hydration capacity index}

The hydration capacity index of the N, C and D black rice flour samples was measured as described by Rasper and DeMan (1980). Briefly, rice flour $(0.4 \mathrm{~g})$ was mixed with $10 \mathrm{~mL}$ of distilled water in a plastic centrifuge tube and capped. The tube was shaken for 15 min using a vortex (Vortex-Genie 2, Scientific Industries, USA) and let stand for $10 \mathrm{~min}$. Solid particles were separated by centrifugation at $6,000 \mathrm{rpm}$ for $15 \mathrm{~min}$. The supernatant was discarded and the solid precipitate in the centrifuge tube was weighed. The hydration index was calculated using the following equation:

$$
\text { Hydration index }=(W 3-W 2) / W 1
$$

where $W 1$ is the weight of rice flour, $W 2$ is the weight of the centrifuge tube, and $W 3$ is the weight of the centrifuge tube with the solid precipitate of the hydrated rice flour.

\section{Water solubility index}

Water solubility of N, C and D black rice flour was determined using the method described by Wang et al. (2011). The black rice flour $(2.5 \mathrm{~g})$ was weighed in a plastic centrifuge tube and $30 \mathrm{~mL}$ of distilled water was added and mixed thoroughly using a glass rod. The mixture was centrifuged at 6,000 rpm for $10 \mathrm{~min}$. The soluble supernatant was collected and dried in a hot air oven at $105 \pm 2{ }^{\circ} \mathrm{C}$ until constant weight. The dry weight (dw) of the soluble fraction was determined. Water solubility of the rice flour was calculated using the following equation:

Water solubility $(\%)=(\mathrm{dw}$ of the soluble fraction/rice flour $\mathrm{dw}) \times 100$

\section{Chemical compositions}

The N, C and D black rice flours were analyzed for chemical compositions. The moisture content determined using the loss-on-drying method (Official Method 40.1.04) (AOAC, 2005) and the fat content was extracted using the soxhlet extraction method (Official Method 40.1.05) (AOAC, 2005). The fiber content was determined using the acid and base digestion method (Official Method 40.1.07) (AOAC, 2005) and the ash content was analyzed using the method described in the Official Method 40.1.03 (AOAC, 2005). Carbohydrate content was calculated from the difference. The protein content was analyzed using Kjeldahl method (Official Method 40.1.06) (AOAC, 2005). 


\section{Extraction of anthocyanins}

Anthocyanins in the N, C and D black rice flours were extracted using the method described by Abdel-Aal et al. (2006) with some modifications. Black rice flour $(5 \mathrm{~g})$ was extracted with $30 \mathrm{~mL}$ of methanol acidified with $0.15 \mathrm{~N} \mathrm{HCl}(85: 15 \mathrm{v} / \mathrm{v})$. The mixture was stirred using a magnetic stirrer for $1 \mathrm{~h}$. The non-extractable solid fraction was separated by centrifugation at $6,000 \mathrm{rpm}$ for $15 \mathrm{~min}$ at $25^{\circ} \mathrm{C}$. The supernatant was collected and the solid fraction was re-extracted twice more using the same procedure. The supernatants were combined and the solvent was removed using a rotary evaporator at $40{ }^{\circ} \mathrm{C}$. The crude extract was stored at $15 \pm 1{ }^{\circ} \mathrm{C}$ for further analysis.

\section{Determination of total anthocyanin content (TAC)}

The TAC of the extracts was measured using a $\mathrm{pH}$ differential method as described by Giusti and Wrolstad (2001). Briefly, each $0.1 \mathrm{~mL}$ of the crude extract solution was diluted in separate buffered solutions $(3 \mathrm{~mL})$ at $\mathrm{pH} 1.0$ and 4.5 and the absorbances at 510 and $700 \mathrm{~nm}$ were measured. The total absorbance values were calculated using the following equation:

$$
\text { Total absorbance }(A)=\left(A_{510}-A_{700}\right)_{\mathrm{pH} 1.0}-\left(A_{510}-A_{700}\right)_{\mathrm{pH} 4.5}
$$

where $A_{510}$ is the absorbance at $510 \mathrm{~nm}$ and $A_{700}$ is the absorbance at $700 \mathrm{~nm}$. The obtained $A$ value was used to calculate for TAC using the folloing equation:

$$
\mathrm{TAC}(\mathrm{mg} / \mathrm{L})=(A \times M W \times D F \times 1000) /(\varepsilon \times 1)
$$

where $A$ is the total absorbance obtained from the calculation, $M W$ is the molecular weight of cyanidin-3-glucoside (449.2), DF is dilution coefficient, and $\varepsilon$ is molar absorptivity of cyanidin-3-glucoside $(26,900)$. The result was expressed as $\mathrm{mg} / 100 \mathrm{~g} \mathrm{dw}$.

\section{HPLC analysis of anthocyanin content}

Anthocyanin content in the crude extract was determined using an HPLC-PDA (LC-10AD VP, Shimadzu, Japan) equipped with a reversed phase C-18 HPLC column (Inertsil ${ }^{\circledR}$ ODS-3, $4.6 \times 250 \mathrm{~mm}, 5 \mu \mathrm{m}$ ). The mobile phase solvents were $0.1 \%$ formic acid (A) and $0.1 \%$ formic acid in acetonitrile (B). Step gradient elution was performed as follows: 0-15 min; 10-20\% B, 15-16 min; $90 \% \mathrm{~B}, 16-17 \mathrm{~min} ; 90 \% \mathrm{~B}, 17-18 \mathrm{~min} ; 10 \% \mathrm{~B}, 18-21 \mathrm{~min} ; 10 \% \mathrm{~B}$. The injection volume was $100 \mu \mathrm{L}$, the flow rate was $1 \mathrm{~mL} / \mathrm{min}$, and column 
temperature was $35^{\circ} \mathrm{C}$. Anthocyanins were detected by absorbance at $520 \mathrm{~nm}$ and related to corresponding anthocyanin standards. The contents of anthocyanins were calculated from a standard plot of the anthocyanin authentic standards.

\section{LC-MS/MS identification of specific anthocyanins}

The anthocyanins in the crude extract were analyzed using an LC-MS/MS (6540 UHD Accurate Mass Q-TOF ESI-MS/MS, Agilent Technologies) equipped with a reversed phase C-18 HPLC column (Inertsil ${ }^{\circledR}$ ODS-3, $4.6 \times 250 \mathrm{~mm}, 5 \mu \mathrm{m})$. Mobile phase solvents were $0.1 \% \mathrm{v} / \mathrm{v}$ formic acid in water (A) and $0.1 \% \mathrm{v} / \mathrm{v}$ formic acid in acetonitrile (B). Gradient elution program was used to separate anthocyanins by increasing the ratio of $\mathrm{B}$ from $5 \%(0 \mathrm{~min})$ to $95 \%(30 \mathrm{~min})$. The injection volume was $5 \mu \mathrm{L}$. The separation conditions were $0.5 \mathrm{~mL} / \mathrm{min}$ for the flow rate at $35^{\circ} \mathrm{C}$ of column temperature. The mass spectrometer was performed with positive ESI mode, 100 to $1,200 \mathrm{~m} / z$ of mass scanning range, 4.0 spectra/sec of scan rate, $350{ }^{\circ} \mathrm{C}$ of gas temperature, and $10 \mathrm{~L} / \mathrm{min}$ of gas flow. The collision energy was set at 10, 20 and $40 \mathrm{~V}$ when performing fragmentation (MS/MS). Peak identification was performed by comparison of the retention time, mass spectra and fragmentation patterns with reference compounds, published data and library search; MassHunter METLIN metabolite PCD/PCDL (Agilent Technologies). Molecular formula was generated by Agilent MassHunter Qualitative Analysis Software B 06.0.

\section{DPPH scavenging activity}

The antioxidant activity of the crude extracts against 1,1-diphenyl-2picrylhydrazyl (DPPH) was determined (Yamaguchi et al., 1998). The extract solution $(0.1 \mathrm{~mL})$ was mixed with $3 \mathrm{~mL} \mathrm{DPPH}$ solution $(0.1 \mathrm{mM}$ in $95 \% \mathrm{v} / \mathrm{v}$ ethanol) and the mixture was then incubated at room temperature $\left(30 \pm 2{ }^{\circ} \mathrm{C}\right)$ in the dark for $30 \mathrm{~min}$. The mixture was measured for absorbance at $515 \mathrm{~nm}$ using a spectrophotometer (HACH DR-4000U, USA). The scavenging activity was expressed as the percentage scavenging of the extract as related to the control and was calculated as follows:

$$
\text { Scavenging activity }(\%)=\left[\left(A_{\text {control }}-A_{\text {sample }}\right) / A_{\text {control }}\right] \times 100
$$

where $A_{\text {sample }}$ is the absorbance of the test solution (the extract solution was used) and $A_{\text {control }}$ is the absorbance of the control solution (distilled water was used instead of the extract solution). 


\section{Statistical analysis}

The data were expressed as means \pm standard deviation (SD) from at least triplicate experiments. Statistical analysis was performed using SPSS v 16.0 (SPSS Inc., Chicago, Illinois, USA), and statistical significance was assessed using one-way ANOVA. Significant different of the mean values was established using by Duncan's multiple range test at $95 \%$ confidence level $(P \leq 0.05)$.

\section{RESULTS}

\section{Color profiles of rice samples}

Color parameters of native (N), cooked (C), and drum-dried (D) black rice flour are shown in Table 1 . The $L^{*}$ coordinate indicates black $(-) /$ white $(+)$ contrast. The lightness $\left(L^{*}\right)$ of both ND and HN was decreased by both cooking $\left(L^{*}=27.0\right)$ and drum-drying $\left(L^{*}=24.1\right)$.

Table 1. Color, hydration, and solubility of the glutinous (Niew Dam; ND) and non-glutinous (Hom Nil; HN) black rice flour at different pregelatinization processes.

\begin{tabular}{ccccccc}
\hline \multirow{2}{*}{ Rice } & \multicolumn{4}{c}{ Color parameters } & \multirow{2}{*}{ Hydration (\%) } & Solubility (\%) \\
\cline { 2 - 4 } & $\boldsymbol{L}^{*}$ & $\boldsymbol{a}^{*}$ & $\boldsymbol{b}^{*}$ & & & \\
\cline { 2 - 3 } ND-N & $48.4^{\mathrm{a}} \pm 0.5$ & $2.2^{\mathrm{f}} \pm 0.0$ & $1.1^{\mathrm{b}} \pm 0.1$ & & $323^{\mathrm{d}} \pm 13$ & $3.6^{\mathrm{c}} \pm 0.2$ \\
ND-C & $27.0^{\mathrm{c}} \pm 0.4$ & $5.8^{\mathrm{d}} \pm 0.4$ & $3.1^{\mathrm{b}} \pm 0.4$ & & $863^{\mathrm{b}} \pm 32$ & $7.0^{\mathrm{a}} \pm 0.5$ \\
ND-D & $24.1^{\mathrm{d}} \pm 0.5$ & $7.8^{\mathrm{b}} \pm 0.3$ & $1.8^{\mathrm{b}} \pm 0.1$ & & $925^{\mathrm{a}} \pm 4$ & $4.5^{\mathrm{b}} \pm 0.1$ \\
\hline HN-N & $48.8^{\mathrm{a}} \pm 1.2$ & $3.1^{\mathrm{e}} \pm 0.1$ & $4.9^{\mathrm{a}} \pm 0.4$ & & $274^{\mathrm{e}} \pm 10$ & $3.1^{\mathrm{d}} \pm 0.1$ \\
HN-C & $34.7^{\mathrm{b}} \pm 0.7$ & $6.6^{\mathrm{c}} \pm 0.1$ & $6.3^{\mathrm{a}} \pm 0.4$ & & $693^{\mathrm{c}} \pm 12$ & $2.3^{\mathrm{e}} \pm 0.2$ \\
HN-D & $35.6^{\mathrm{b}} \pm 0.1$ & $8.5^{\mathrm{a}} \pm 0.1$ & $5.9^{\mathrm{a}} \pm 0.2$ & & $902^{\mathrm{a}} \pm 5$ & $2.6^{\mathrm{de}} \pm 0.1$ \\
\hline
\end{tabular}

Note: ${ }^{\text {a-e }}$ indicate significant differences $(P \leq 0.05)$ of the mean values in the same column. ND-N: Niew Dam Native; ND-C: Niew Dam Cooked; ND-D: Niew Dam Drum-dried; HN-N: Hom Nil Native; HN-C: Hom Nil Cooked; HN- D: Hom Nil Drum-dried.

\section{Water solubility and water hydration capacity indexes}

Water hydration of ND-N was significantly higher $(P \leq 0.05)$ than that of HN-N (Table 1). The percentage water hydration of ND-C was also significantly higher $(P \leq 0.05)$ than that of the HN-C but hydration values of ND-D and HN-D were similar. Water hydration of the drum-dried ND rice increased by 
approximately 2.7 -fold as compared to the native ND rice whereas a larger increase of 3.3-fold was found with the $\mathrm{HN}$ rice.

Water solubility of ND-C-and ND-D increased significantly as compared to ND-N in contrast to $\mathrm{HN}-\mathrm{C}$ and $\mathrm{HN}-\mathrm{D}$ where values decreased compared to HN-N. Overall, the water solubility of the ND rice was generally higher than that of the corresponding $\mathrm{HN}$ rice.

\section{Chemical compositions}

The moisture content of both ND-N and HN-N was significantly decreased by drum-drying (Table 2) indicating a loss of moisture during the high temperature $\left(130^{\circ} \mathrm{C}\right)$ modification. The fat content of ND-N was slightly higher than that of $\mathrm{HN}-\mathrm{N}$. In both $\mathrm{ND}$ and $\mathrm{HN}$ rice flour fat content was significantly $(P \leq 0.05)$ reduced by cooking and especially by drum-drying (Table 2). ND-N contained the highest fiber content but the heat treatments had no effect on the fiber content of $\mathrm{HN}$ which ranged from 2.2-2.3\%. For protein, ash, and carbohydrate contents, the drum dried sample of both of the cultivars tended to show the highest values among the different treatments (Table 2).

Table 2. Chemical compositions of glutinous (Niew Dam; ND) and non-glutinous (Hom Nil; HN) black rice flour at different pregelatinization processes.

\begin{tabular}{ccccccc}
\hline \multirow{2}{*}{ Rice } & \multicolumn{5}{c}{ Composition (\% DW) } \\
\cline { 2 - 7 } & Moisture & Fat & Protein & Fiber & Ash & Carbohydrate \\
\hline ND-N & $10.7^{\mathrm{a}} \pm 0.36$ & $3.6^{\mathrm{a}} \pm 0.1$ & $10.4^{\mathrm{c}} \pm 0.1$ & $3.5^{\mathrm{a}} \pm 0.2$ & $1.67^{\mathrm{bc}} \pm 0.03$ & $70.1^{\mathrm{b}} \pm 0.3$ \\
ND-C & $7.71^{\mathrm{c}} \pm 0.06$ & $3.4^{\mathrm{b}} \pm 0.1$ & $11.1^{\mathrm{b}} \pm 0.2$ & $2.2^{\mathrm{b}} \pm 0.2$ & $1.64^{\mathrm{c}} \pm 0.01$ & $73.9^{\mathrm{b}} \pm 0.4$ \\
ND-D & $3.30^{\mathrm{e}} \pm 0.06$ & $2.6^{\mathrm{d}} \pm 0.1$ & $11.5^{\mathrm{a}} \pm 0.2$ & $2.3^{\mathrm{b}} \pm 0.1$ & $1.76^{\mathrm{ab}} \pm 0.02$ & $78.6^{\mathrm{a}} \pm 0.3$ \\
\hline HN-N & $9.43^{\mathrm{b}} \pm 0.14$ & $3.4^{\mathrm{b}} \pm 0.1$ & $11.1^{\mathrm{b}} \pm 0.1$ & $2.5^{\mathrm{b}} \pm 0.2$ & $1.78^{\mathrm{ab}} \pm 0.07$ & $71.9^{\mathrm{c}} \pm 0.4$ \\
HN-C & $7.37^{\mathrm{d}} \pm 0.13$ & $3.2^{\mathrm{c}} \pm 0.1$ & $11.3^{\mathrm{ab}} \pm 0.3$ & $2.3^{\mathrm{b}} \pm 0.1$ & $1.73^{\mathrm{ab}} \pm 0.05$ & $74.1^{\mathrm{c}} \pm 0.4$ \\
HN-D & $3.05^{\mathrm{e}} \pm 0.02$ & $2.5^{\mathrm{d}} \pm 0.1$ & $11.6^{\mathrm{a}} \pm 0.1$ & $2.2^{\mathrm{b}} \pm 0.1$ & $1.85^{\mathrm{a}} \pm 0.04$ & $78.8^{\mathrm{a}} \pm 0.1$ \\
\hline
\end{tabular}

Note: a-e indicate significant differences $(P \leq 0.05)$ of the mean values in the same column. ND-N: Niew Dam Native; ND-C: Niew Dam Cooked; ND-D: Niew Dam Drum-dried; HN-N: Hom Nil Native; HN-C: Hom Nil Cooked; HN- D: Hom Nil Drum-dried

\section{Total anthocyanin content (TAC)}

The glutinous rice, ND-N, contained approximately 13-fold higher anthocyanin concentration than the non-glutinous cultivar HN-N (Table 3). The black glutinous rice cultivar also had the highest TAC followed by ND-C 
and ND-D. The same trend was found with the black non-glutinous rice in which HN-N contained the highest TAC followed by HN-C and HN-D. The TAC in both cultivars decreased considerably by both cooking and by drumdrying by as much as $91-92 \%$. With the high thermal drying process $\left(130^{\circ} \mathrm{C}\right)$ TAC was as only $9 \%$ (ND-D) and $8 \%$ (HN-D) of the initial TAC content.

Table 3. TAC values and percentage retention of the specific anthocyanins analyzed by HPLC-DAD in the black rice flour.

\begin{tabular}{|c|c|c|c|c|c|c|}
\hline \multirow[t]{2}{*}{ Rice } & \multirow{2}{*}{$\begin{array}{c}\text { TAC } \\
(\mathrm{mg} / \mathbf{1 0 0} \mathrm{g} \mathrm{dw})\end{array}$} & \multirow{2}{*}{$\begin{array}{l}\text { \% Retention } \\
\text { of TAC* }\end{array}$} & \multicolumn{2}{|c|}{$\begin{array}{l}\text { Anthocyanin content } \\
\quad(\mathrm{mg} / \mathrm{g} \mathrm{dw})\end{array}$} & \multicolumn{2}{|c|}{$\%$ Retention* } \\
\hline & & & C3G & P3G & C3G & P3G \\
\hline ND-N & $4,099^{a} \pm 106$ & 100 & $1,213^{a} \pm 97$ & $277^{a} \pm 17$ & 100 & 100 \\
\hline ND-C & $452^{b} \pm 17$ & 11 & $437^{b} \pm 6$ & $29^{b} \pm 3$ & 36 & 10 \\
\hline ND-D & $358^{\mathrm{c}} \pm 36$ & 9 & $568^{\mathrm{b}} \pm 35$ & $32^{b} \pm 3$ & 47 & 11 \\
\hline HN-N & $305^{c} \pm 31$ & 100 & $7.86^{c} \pm 0.18$ & $0.90^{\mathrm{c}} \pm 0.01$ & 100 & 100 \\
\hline HN-C & $95^{\mathrm{d}} \pm 6$ & 31 & $2.54^{\mathrm{d}} \pm 0.02$ & $0.75^{\mathrm{d}} \pm 0.06$ & 32 & 83 \\
\hline HN-D & $23^{e} \pm 3$ & 8 & $3.26^{\mathrm{d}} \pm 0.51$ & $0.44^{\mathrm{e}} \pm 0.02$ & 41 & 49 \\
\hline
\end{tabular}

Note: ${ }^{\text {a-e }}$ indicate significant differences $(P \leq 0.05)$ of the mean values in the same column. * Percentage retention was calculated as a proportion of the initial unprocessed values of each native rice (ND-N or HN-N) ND-N: Niew Dam Native; ND-C: Niew Dam Cooked; ND-D: Niew Dam Drum-dried; HN-N: Hom Nil Native; HN-C: Hom Nil Cooked; HN-D: Hom Nil Drum-dried

\section{HPLC analysis of anthocyanin contents}

The retention of major anthocyanins, $\mathrm{C} 3 \mathrm{G}$ and $\mathrm{P} 3 \mathrm{G}$, in the native, cooked, and drum-dried black rice flour was analyzed using HPLC. The standard plots of the anthocyanin authentic standards showed that the squared correlation coefficients $\left(r^{2}\right)$ for $\mathrm{C} 3 \mathrm{G}$ and $\mathrm{P} 3 \mathrm{G}$ were 0.9997 and 0.9983 , respectively (data not shown). The major anthocyanin derivatives, C3G ( $>80 \%)$ and $\mathrm{P} 3 \mathrm{G}(<20 \%)$, were found in the unprocessed samples of both black rice cultivars (Table 3). The ND rice contained markedly higher $\mathrm{C} 3 \mathrm{G}$ and $\mathrm{P} 3 \mathrm{G}$ concentrations than the $\mathrm{HN}$ rice.

The contents of $\mathrm{C} 3 \mathrm{G}$ in $\mathrm{ND}-\mathrm{N}$ and $\mathrm{HN}-\mathrm{N}$ were significantly $(P \leq 0.05)$ decreased by cooking (providing 36 and $32 \%$ retention, respectively). However, a further treatment by drum-drying did not significantly $(P>0.05)$ reduce the $\mathrm{C} 3 \mathrm{G}$ content in either ND-D or in HN-D (Table 3). 
After cooking, the P3G contents in both ND-C and HN-C were reduced (to $10 \%$ and $83 \%$ of the uncooked values, respectively). However, while the P3G content in ND-D remained unchanged $(P>0.05)$, this content in HN-D significantly decreased after drum drying (Table 3 ).

\section{DPPH scavenging activity}

The black, glutinous rice variety, ND, exhibited better DPPH scavenging ability than the non-glutinous HN rice variety (Figure 1). The DPPH scavenging activity of both cultivars was significantly decreased by cooking but in ND was maintained after the drum-drying in contrast with $\mathrm{HN}$ where it further decreased.

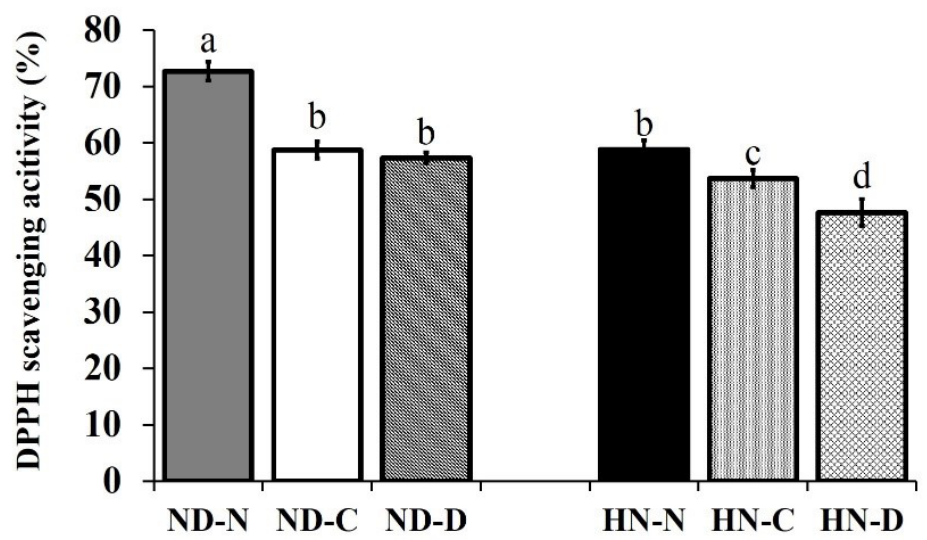

Figure 1. The DPPH scavenging activity of native (N), cooked (C), and drum-dried (D) of glutinous (Niew Dam; ND) and non-glutinous (Hom Nil; HN) rice extracts. ${ }^{a-d a b o v e ~ t h e ~ b a r ~ g r a p h s ~ i n d i c a t e ~}$ statistical differences $(P \leq 0.05)$ of all samples.

\section{Identification of anthocyanins by LC-MS/MS}

Anthocyanins in the two cultivars, ND and HN, were analyzed using LC-Q-TOF-MS/MS. The molecular ion of anthocyanin derivatives and their fragmentations are presented in Table 4 and LC-Q-TOF-MS/MS base peak chromatograms are shown in Figure 2. The anthocyanin profiles of the two cultivars were similar and shared three common anthocyanin derivatives: cyanidin-diglucoside $(\mathrm{CdG})$, cyanidin-3-glucoside $(\mathrm{C} 3 \mathrm{G})$, peonidin-3-glucoside (P3G), and two aglycones: cyanidin (Cy), and peonidin (Pn). 

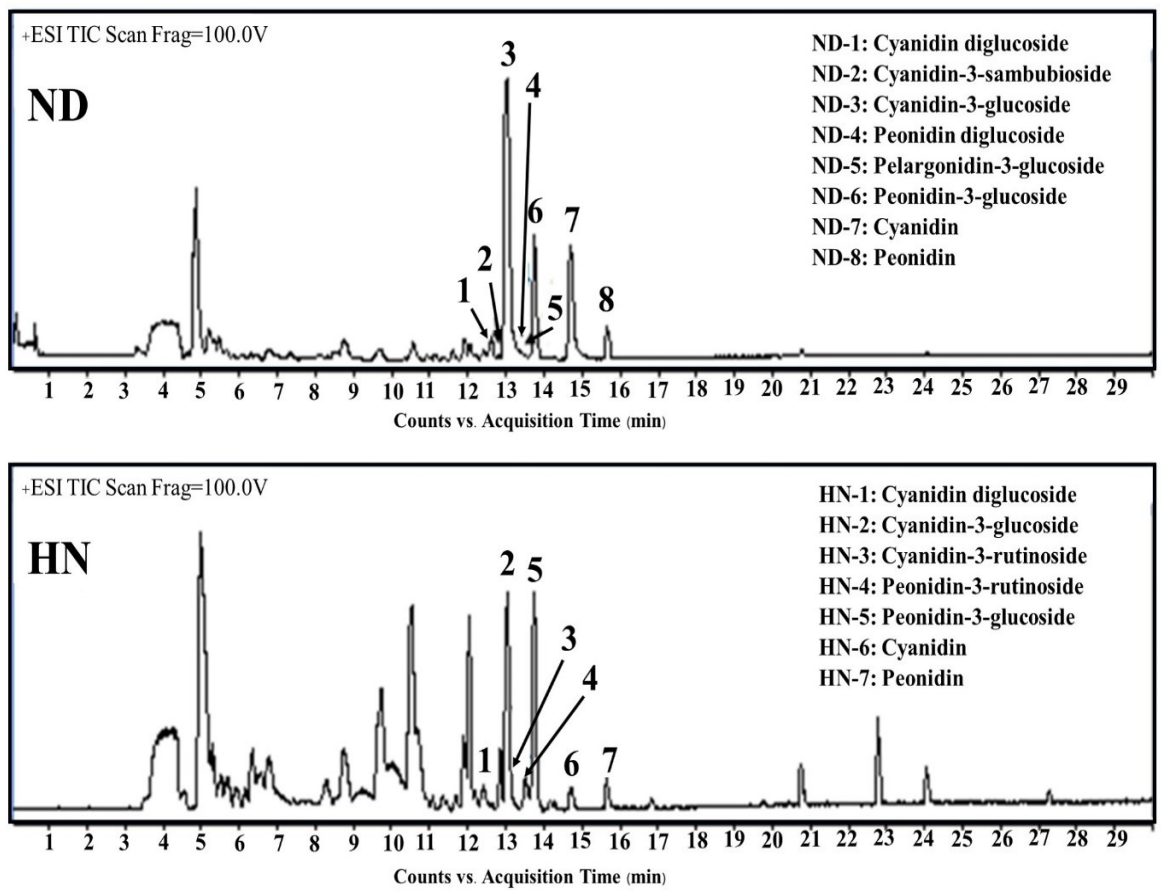

Figure 2. HPLC-Q-TOF-MS/MS base peak chromatograms in positive mode of black rice extracts at a concentration of $50 \mathrm{mg} / \mathrm{mL}$ of glutinous (Niew Dam; ND) and non-glutinous (Hom Nil; HN) rice extracts.

Eight anthocyanins were identified in ND using MS (Table 4). Cyanidin-3-sambubioside (peak No. ND-2) was separated at $12.82 \mathrm{~min}$ and showed positively charged molecular mass at $\mathrm{m} / \mathrm{z} 581.15$ with a fragment ion at $\mathrm{m} / \mathrm{z} 287.05$. The compound with a mass at $\mathrm{m} / \mathrm{z} 625.17$ and with a fragment ion at $\mathrm{m} / \mathrm{z} 301.07$ was identified as peonidin diglucoside (peak No. ND-4). Pelargonidin-3-glucoside (peak No. ND-5) has not previously been identified in glutinous ND rice. It had a mass ion at $\mathrm{m} / \mathrm{z} 433.11$ and a fragment ion at $\mathrm{m} / \mathrm{z}$ 271.06 .

Seven anthocyanins were identified in $\mathrm{HN}$ rice and two of these anthocyanins were different from those in ND rice. Mass ion at $\mathrm{m} / z 595.16$ and $m / z 609.18$ with fragment ion at $m / z 287.05$ (peak No. HN-3) and $m / z 301.08$ (peak No. HN-4) were identified as cyanidin-3-rutinoside and peonidin3-rutinoside, respectively. 


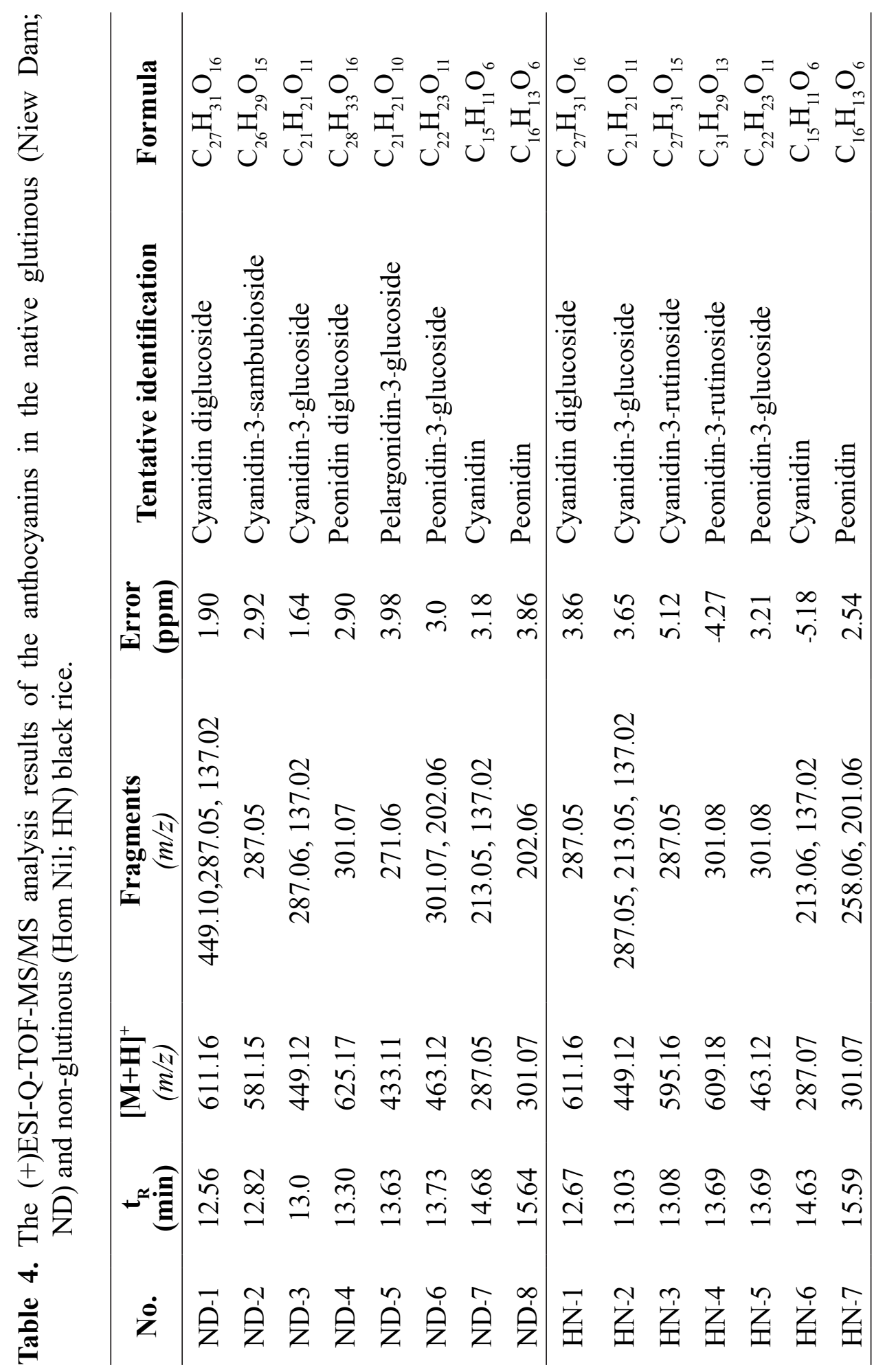




\section{DISCUSSION}

The ND rice had a considerable higher anthocyanin content than that of the $\mathrm{HN}$ rice. In previous studies, high temperature and $\mathrm{pH}$ have been shown to be major factors that cause a decrease of anthocyanin content in grains (Ekici et al., 2014). Hiemori et al. (2009), for example, reported that cooking of black rice using conventional methods destroyed anthocyanins by more than $70 \%$, which is consistent with the results found in this study.

Consequently, it was found that the percentage retention of TAC for both ND and $\mathrm{HN}$ rice was decreased consecutively through the pregelatinization process. The ND-D had significantly higher TAC value than that of the HN-D due to the remarkably high TAC of ND-N. Cooking significantly decreased the TAC value of the rice as the anthocyanins were exposed to high temperature for a long time. Both samples retained TAC content to only 8-9\% after consecutive cooking and drum drying. Yamuangmorn et al. (2018) also report a 67-89\% decrease of anthocyanin content after high moisture cooking. The drum-drying was conducted at a high temperature $\left(130^{\circ} \mathrm{C}\right)$ over a short period $(30-40 \mathrm{sec})$. The thermal degradation of the anthocyanin is dependent on its half-life. Hou et al. (2013) reported that the half-life of anthocyanin at $100{ }^{\circ} \mathrm{C}$ and $\mathrm{pH} 6.0$ was $0.62 \mathrm{~h}$. For this reason, the proportion of remaining anthocyanin, compared with the initial anthocyanin content, in ND-D (which contained significantly higher initial TAC than HN) was higher than that of HN-D. This finding was supported by Melini et al. (2019) who found that the anthocyanin content of cooked rice with a low initial anthocyanin content decreased insignificantly while the decrease was approximately $48-50 \%$ for the rice with higher initial anthocyanin content.

The $\mathrm{C} 3 \mathrm{G}$ and $\mathrm{P} 3 \mathrm{G}$ contents (the two major individual anthocyanins identified in ND and HN), were decreased by cooking while drum-drying had an insignificant effect. Both $\mathrm{C} 3 \mathrm{G}$ and $\mathrm{P} 3 \mathrm{G}$ are heat labile molecules (Ekici et al., 2014). The half-lifes of $\mathrm{C} 3 \mathrm{G}$ and $\mathrm{P} 3 \mathrm{G}$ at $100^{\circ} \mathrm{C}$ have been calculated to be 0.62 and $0.53 \mathrm{~h}$ (Hou et al., 2013), respectively. Thus, the high temperature but short time of the drum-drying method is likely to be the reason for the insignificant reduction of these anthocyanins in that treatment. Hiemori et al. (2009) similarly showed that 20 min cooking of black rice produced a smaller reduction in the contents of both $\mathrm{C} 3 \mathrm{G}$ and $\mathrm{P} 3 \mathrm{G}$ than that of 90 min cooking. Melini et al. (2019) also reported a decrease of anthocyanin content in black rice after it was cooked, where the reduction in $\mathrm{C} 3 \mathrm{G}$ was less than the reduction in P3G. Moreover, the loss of both $\mathrm{C} 3 \mathrm{G}$ and $\mathrm{P} 3 \mathrm{G}$ tended to relate to their initial contents, as one with a greater initial content had a significantly greater decrease in its content, similar to the result for P3G in this study. 
The LC-Q-TOF-MS/MS analysis showed that the anthocyanin profile in the two rice cultivars were mostly similar. The anthocyanins $\mathrm{CdG}, \mathrm{C} 3 \mathrm{G}$, P3G, and two aglycones (Cy and Pn) were identified. These anthocyanins and aglycones, have been previously identified in black rice extracts (Hyun and Chung, 2004; Hiemori et al., 2009; Pereira-Caro et al., 2013). The identification of-cyanidin-3-sambubioside in ND rice was firstly tentatively identified in this study. Cyanidin-3-sambubioside was previously identified in elderberry or blueberry (Wu et al., 2002). Two anthocyanin rutinoside derivatives including cyanidin-3-rutinoside and peonidin-3-rutinoside, were previously reported by Abdel-Aal et al. (2006) and Hou et al. (2013) and were only identified in the $\mathrm{HN}$ rice in this study.

The DPPH antioxidant activity of the extracts from both cultivars was consecutively decreased by cooking and by drum-drying. This decrease was consistent with the TAC values and with the values for the contents of the individual anthocyanins. This indicates that anthocyanins could play a major role on the antioxidant activity in rice samples. Radovanović and Radovanović (2010) similarly showed that DPPH scavenging activity of an anthocyanin-rich extract positively correlated with TAC value.

The effects of high-temperature modification processes on the changes in anthocyanin content and in some important physical properties of pregelatinized black glutinous (ND) and black non-glutinous $(\mathrm{HN})$ rice was evaluated. The changes in the color of the treated-rice were obvious. After cooking and drum drying, the lightness of the processed ND rice decreased while it increased in the $\mathrm{HN}$ rice. The ND rice had significantly higher anthocyanin content than the $\mathrm{HN}$ rice, resulting in more anthocyanin being released, as shown by increased $a^{*}$ value. As a result, the color of the rice became darker. An increase of the $a^{*}$ value along with a decrease of the $b^{*}$ value was also found in drum-dried Riceberry, an anthocyanin-rich black non-glutinous rice (Wiryawattana et al., 2018).

Water hydration of the cooked rice flour from both cultivars was increased by approximately 2.5-2.7 fold compared with the hydration of the unprocessed samples. However, the hydration of the ND was approximately 1.2 times greater than that of the $\mathrm{HN}$, in both the native and cooked samples. Amylopectin content plays a major role in water hydration as it absorbs water faster than amylose (Lai, 2001; Juhász and Salgó, 2008). However, the two-step high temperature treatments (cooking and drum-drying) increased the hydration of both cultivars to similar, very high values. In this treatment it is likely that the amylopectin and amylose contents had no effect on hydration behavior due to the disruption of starch crystallization. The association between the disruption 
of the starch crystallinity and the increase of water hydration and water solubility was discussed by Cooke and Gidley (1992), Lai (2001), and Patindol et al. (2013).

The water solubility values of ND rice were higher than those for HN rice in every step of the modification process. Amylopectin, a major fraction in ND rice, is known to swell faster than the crystalline amylose (Juhász and Salgó, 2008). Consequently, water-soluble fractions (including amylose) are known to be expelled to the water body resulting in high water solubility. The water solubility of the drum-dried ND rice was significantly higher (1.2 fold) than that of the unprocessed grains. In contrast, the water solubility of $\mathrm{HN}$ tended to decrease but insignificantly as compared to the unprocessed grains. Lai (2001) has previously reported that the water solubility of hydrothermally-treated glutinous rice increased while it decreased for the non-glutinous one, as found in this study. These results are also similar to those of Wiryawattana et al. (2018) who reported that the water solubility of drum-dried non-glutinous rice was slightly decreased (by approximately 1.1 fold) compared to native rice. From both studies, the swelling index of the heat-treated rice were increased. Thus, the water solubility of the $\mathrm{HN}$ as a non-glutinous rice, was slightly decreased as the amylose was gelatinized, which increased its swelling property resulting in decreased its solubility. On the other hand, the water-soluble gelatinized amylose, a smaller fraction, in the ND rice was expelled from the swelled amylopectin, a larger fraction, resulting in the increase of the water solubility.

\section{CONCLUSION}

Pregelatinized rice flours from glutinous and non-glutinous black rice were successfully prepared through cooking and the use of a drum-drying processes. The color of pregelatinized rice in cultivars of both rice types changed toward red color due to the leaching of anthocyanins from the rice bran. The hydration properties of the rice flours increased consecutively during this modification. Pregelatinized rice flours from both cultivars showed similar hydration properties. The solubility of the flours decreased after cooking and drum drying, however, solubility of the drum-dried glutinous rice was greater than that of the non-glutinous one. Total anthocyanin and two major anthocyanins, the 3-glucosides of cyanidin and peonidin, were significantly decreased during the pregelatinization process due to thermal degradation. The reduction of the anthocyanin content also resulted in a decrease in antioxidant activity. Mass spectrometric analysis revealed that the glutinous rice contained eight anthocyanins, where cyanidin-3-sambioside was identified for the first time 
as occurring in rice. Seven anthocyanins were identified in the non-glutinous $\mathrm{HN}$ cultivar, but the rutinoside derivatives that were identified were not found in the glutinous rice cultivar. The pregelatinized Thai black rice grains were, therefore, physically improved while the beneficial anthocyanins were still preserved, especially in non-glutinous rice flour, albeit at reduced concentrations. Both pregelatinized glutinous and non-glutinous Thai black rice could be utilized as functional healthy ingredients to develop healthier food products.

\section{REFERENCES}

Abdel-Aal, E.S.M., Young, J.C., and Rabalski, I. 2006. Anthocyanin composition in black, blue, pink, purple, and red cereal grains. Journal of Agricultural and Food Chemistry. 54(13): 4696-4704. https://doi.org/10.1021/jf0606609

AOAC. 2005. Official methods of analysis $\left(18^{\text {th }}\right)$. Association of Official Analytical Chemists, Arlington, Virginia.

Cooke, D., and Gidley, M.J. 1992. Loss of crystalline and molecular order during starch gelatinisation: origin of the enthalpic transition. Carbohydrate Research. 227: 103-112. https://doi.org/10.1016/00086215(92)85063-6

Ekici, L., Simsek, Z., Ozturk, I., Sagdic, O., and Yetim, H. 2014. Effects of temperature, time, and $\mathrm{pH}$ on the stability of anthocyanin extracts: prediction of total anthocyanin content using nonlinear models. Food Analytical Methods. 7(6): 1328-1336. https://doi.org/10.1007/ s12161-013-9753-y

Giusti, M.M., and Wrolstad, R.E. 2001. Characterization and measurement of anthocyanins by UV-visible spectroscopy. In: Wrolstad, R.E., editor. Current protocols in food analytical chemistry. John Wiley \& Sons, New York. p.F1.2.1-F1.2.13. https://doi.org/10.1002/0471142913.faf 0102s00

He, J., and Giusti, M.M. 2010. Anthocyanins: natural colorants with health-promoting properties. Annual Review of Food Science and Technology. 1(1): 163-187.https://doi.org/10.1146/annurev.food.080708. 100754

Hiemori, M., Koh, E., and Mitchell, A.E. 2009. Influence of cooking on anthocyanins in black rice (Oryza sativa L. japonica var. SBR). Journal of Agricultural and Food Chemistry. 57(5): 1908-1914. https://doi.org/10.1021/jf803153z 
Hou, Z., Qin, P., Zhang, Y., Cui, S., and Ren, G. 2013. Identification of anthocyanins isolated from black rice (Oryza sativa L.) and their degradation kinetics. Food Research International. 50(2): 691-697. https://doi.org/10.1016/j.foodres.2011.07.037

Hyun, J.W., and Chung, H.S. 2004. Cyanidin and malvidin from Oryza sativa cv. Heugjinjubyeo mediate cytotoxicity against human monocytic leukemia cells by arrest of G2/M phase and induction of apoptosis. Journal of Agricultural and Food Chemistry. 52(8): 2213-2217. https://doi.org/ 10.1021/jf030370h

Juhász, R., and Salgó, A. 2008. Pasting behavior of amylose, amylopectin and their mixtures as determined by RVA curves and first derivatives. Starch - Stärke. 60(2): 70-78. https://doi.org/10.1002/star.200700634

Juliano, B.O. 1984. Rice starch: production, properties, and uses. In: Whistler, R.L., Bemiller, J.N., and Paschall, E.F., editors. Starch: chemistry and technology ( $2^{\text {nd }}$ ed). Academic Press, San Diego. p.507-528.

Lai, H. 2001. Effects of hydrothermal treatment on the physicochemical properties of pregelatinized rice flour. Food Chemistry. 72: 455-463. https://doi.org/10.1016/S0308-8146(00)00261-2

Melini, V., Panfili, G., Fratianni, A., and Acquistacci, R. 2019. Bioactive compounds in rice on Italian market: pigmented varieties as a source of carotenoids, total phenolic compounds and anthocyanins, before and after cooking. Food Chemistry. 277: 119-127. https://doi.org/10. 1016/j.foodchem.2018.10.053

Miles, M.J., Morris, V.J., Orford, P.D., and Ring, S.G. 1985. The roles of amylose and amylopectin in the gelation and retrogradation of starch. Carbohydrate Research. 135(2): 271-281. https://doi.org/10.1016/ S0008-6215(00)90778-X

Patindol, J., Shih, F., Ingber, B., Champagne, E., and Boue, S. 2013. Porous rice powder from the precipitation of gelatinized flour or starch paste with ethanol. Starch - Stärke. 65: 296-303. https://doi.org/10.1002/star. 201200134

Pereira-Caro, G., Watanabe, S., Crozier, A., Fujimura, T. Yokota, T., and Ashihara, H. 2013. Phytochemical profile of a Japanese black-purple rice. Food Chemistry. 141: 2821-2827. https://doi.org/10.1016/j.foodchem. 2013.05.100

Radovanović, B., and Radovanović, A. 2010. Free radical scavenging activity and anthocyanin profile of cabernet sauvignon wines from the balkan region. Molecules. 15(6): 4213-4226. https://doi.org/10.3390/molecules 15064213 
Rasper, V.F., and DeMan, J.M. 1980. Measurement of hydration capacity of wheat flour/starch mixtures. Cereal Chemistry. 57: 27-31.

Wadchararat, C., Thongngam, M., and Naivikul, O. 2006. Characterization of pregelatinized and heat moisture treated rice flours. Kasetsart Journal (Natural Science). 40(Supplement): 144-153.

Wang, J., Zhai, W., and Zheng, W. 2011. Preparation of granular cold-watersoluble corn starch by surface modification with poly(ethylene glycol). Starch - Stärke. 63(10): 625-631. https://doi.org/10.1002/star.201100033

Wiriyawattana, P., Suwonsichon, S., and Suwonsichon, T. 2018. Effects of drum drying on physical and antioxidant properties of riceberry flour. Agriculture and Natural Resources. 52: 445-450. https://doi.org/ 10.1016/j.anres.2018.11.008

Wu, X., Cao, G., and Prior, R.L. 2002. Absorption and metabolism of anthocyanins in elderly women after consumption of elderberry or blueberry. The Journal of Nutrition. 132(7): 1865-1871. https://doi.org/ $10.1093 / \mathrm{jn} / 132.7 .1865$

Yamaguchi, T., Takamura, H., Matoba, T., and Terao, J. 1998. HPLC method for evaluation of the free radical-scavenging activity of foods by using 1,1-diphenyl-2-picrylhydrazyl. Bioscience, Biotechnology, and Biochemistry. 62(6): 1201-1204. https://doi.org/10.1271/bbb.62.1201

Yamuangmorn, S., Dell, B., and Prom-u-thai, C. 2018. Effects of cooking on anthocyanin concentration and bioactive antioxidant capacity in glutinous and non-glutinous puple rice. Rice Science. 25(5): 270-278. https://doi.org/10.1016/j.rsci.2018.04.004 